\title{
Influência do horário de coleta, orientação geográfica e dossel na produção de óleo essencial de Cordia verbenacea DC
}

\author{
Manoel Ferreira de Souza \\ Sara Anizelli Manganotti* \\ Patrícia Nery Silva Souza \\ Messulan Rodrigues Meira \\ Christiano da Conceição de Matos \\ Ernane Ronie Martins \\ Universidade Federal de Minas Gerais \\ Avenida Universitária, n. 1000, Campus Universitário \\ CEP 39400-000, Montes Claros - MG, Brasil \\ *Autor para correspondência \\ sara_manganotti@hotmail.com
}

Submetido em 10/03/2010

Aceito para publicação em 28/10/2010

\section{Resumo}

A espécie Cordia verbenacea DC. (Boraginaceae), conhecida popularmente como "Erva Baleeira", tem sido largamente estudada em relação às suas propriedades farmacológicas, sendo confirmado seu potencial como antiinflamatório, analgésico, e anti-ulcerogênico. O objetivo deste trabalho foi verificar o teor de óleo essencial sobre a influência da orientação geográfica e dossel, e horário de coleta da parte aérea de C. verbenacea. As folhas foram obtidas de plantas matrizes do Horto Medicinal do ICA/UFMG, no mês de abril de 2009, em seguida, submetidas à extração do óleo essencial pelo método de hidrodestilação usando o aparelho de Clevenger. Foram conduzidos dois experimentos, em delineamento experimental em blocos casualizados, com cinco repetições. A variável horário de coleta $(8,9,12,15$ e $18 \mathrm{~h})$ foi ajustada regressões polinomiais, e orientação geográfica (norte, sul, leste, oeste) e dossel (apical, médio e basal) utilizou-se arranjo fatorial 4x3 (quatro orientações geográficas e três dosséis). O teor de óleo essencial foi expresso com base na matéria seca da amostra. Houve interação significativa para ambos os fatores avaliados e, os maiores teores de óleo essencial foram obtidos na orientação geográfica norte e sul basal e no horário das $18 \mathrm{~h}$ das plantas amostradas.

Palavras-chave: Cordia verbenacea, Plantas medicinais, Produção de óleo essencial

\section{Abstract}

Influence of time of collection, geographic orientation and canopy on the production of essential oil Cordia verbenacea DC. The species Cordia verbenacea DC. (Boraginaceae), known popularly as "Whaling Herb," has been widely studied in relation to its pharmacological properties, and studies have confirmed its potential as an anti-inflammatory, analgesic and anti-ulcerogenic remedy. The objective was to verify the content of essential oil in shoots of $C$. verbenacea resulting from the influence of geographic orientation, canopy and 
harvesting time. Leaves were taken from mother plants of the Medicinal Garden of ICA / UFMG in April 2009, and then subjected to extraction of essential oil by hydrodistillation method using Clevenger apparatus. Two experiments were conducted in randomized complete block design with five replications. The variable time of collection $(8,9,12,15$ and $18 \mathrm{~h}$ ) was fitted to polynomial regressions for geographical orientation (north, south, east and west) and canopy (upper, middle and basal) using a 4 × 3 factorial arrangement (four geographical orientations and three canopies). The essential oil content was expressed on the basis of the dry matter of the sample. A significant interaction for both factors evaluated and the highest levels of oil were obtained in the north and south geographical orientations and collection time of 18:00 $\mathrm{h}$.

Key words: Cordia verbenacea, Essential oil production, Medicinal plants

\section{Introdução}

No Brasil, observa-se um crescimento do consumo de medicamentos à base de plantas em todas as classes sociais. A demanda maior de fitoterápicos consumidos é para tratamento de problemas do sistema nervoso central, trato digestivo e de doenças respiratórias (NOGUEIRA; WOLFF, 2001). A produção de plantas medicinais representa uma alternativa inovadora e interessante para o agronegócio brasileiro (LOURENZANI et al., 2004). No entanto, os compostos de interesse são metabólitos secundários, que são princípios ativos responsáveis pelos efeitos terapêuticos e biológicos, cuja produção e concentração são influenciadas por fatores ambientais e fisiológicos, sendo este um dos principais obstáculos ao seu processamento nas indústrias de fitomedicamentos e cosméticos (LIMA et al., 2003; ZARONI et al., 2004). Desde o quarto século a.C., existem relatos de normas para a coleta de plantas medicinais (FAIRBAIRN et al., 1961; ROBINSON, 1974). Variações temporais e espaciais no conteúdo total, bem como as proporções relativas de metabólitos secundários em plantas ocorrem em diferentes níveis e, apesar da existência de um controle genético, a expressão pode sofrer modificações resultantes da interação de processos bioquímicos, fisiológicos, ecológicos e evolutivos (LINDROTH et al., 1987; HARTMANN, 1996). De fato, os metabólitos secundários representam uma interface química entre as plantas e o ambiente circundante, portanto, sua síntese é freqüentemente afetada por condições ambientais (KUTCHAN, 2001).

A espécie Cordia verbenacea DC. possui folhas aromáticas, que são utilizadas na medicina popular como anti-inflamatório, analgésico, e anti-ulcerogenico, sob a forma de chás ou infusões para uso interno ou tópico
(LORENZI; MATOS, 2002; SOUZA et al., 2004). Vários estudos têm fornecido a base para a utilização popular desta espécie, confirmando sua atividade antimicrobiana (CARVALHO JR. et al., 2004), antiinflamatória (BASILE et al., 1989; PASSOS et al., 2007) e analgésica (SERTIÉ et al., 2005). Estudos fitoquímicos da parte aérea de $C$. verbenacea identificaram a presença de monoterpenos (CARVALHO JR. et al., 2004), triterpenos e flavonas (Lins et al., 1990). Folhas frescas de C. verbenacea produzem $0,23 \%(\mathrm{v} / \mathrm{w})$ de óleo essencial, apresentando como principais componentes o $\alpha$-pineno $(29,69 \%)$, trans-cariofileno $(25,27 \%)$, alloaromadendrene $(9,99 \%)$ e alfa-humuleno (4,64\%) (Carvalho Jr. et al., 2004).

$\mathrm{Na}$ dinâmica de crescimento, desenvolvimento e estádios fenológicos das espécies vegetais, há alterações bioquímicas e fisiológicas capazes de modificar a elaboração de substâncias biologicamente ativas, nos aspectos qualitativos e quantitativos, influenciando diretamente no teor e na qualidade dos óleos essenciais (TAIZ; ZEIGER, 2004). A utilização de $C$. verbenacea na medicina tradicional, o estudo fitoquímico e a atividade farmacológica comprovada mostram a necessidade de um melhor conhecimento dos fatores que afetam a produção de óleos essenciais. Assim, o ponto da coleta tornase um aspecto fundamental para estudos com plantas medicinais, para a determinação do melhor período, que permita o máximo aproveitamento e apresente melhor qualidade e mínimo de perdas (TESKE; TRENTINI, 1997). Contudo, não existem muitos estudos sobre a influência na produção de metabólitos secundários desta espécie e extração de óleos essenciais (GOBBO-NETO; LOPES, 2007). Neste contexto, o objetivo deste artigo foi avaliar a influência da orientação e dossel e, horário de coleta no teor de óleo essencial de $C$. verbenacea. 


\section{Material e Métodos}

O experimento foi conduzido no horto medicinal do Instituto de Ciências Agrárias da Universidade Federal de Minas Gerais, Montes Claros - MG, localizado nas coordenadas geográficas: latitude $16^{\circ} 40^{\prime} 50.92$ "S e longitude $43^{\circ} 50^{\prime} 22.36^{\prime} \mathrm{W}$, na altitude de $649 \mathrm{~m}$. O clima, segundo a classificação de Köppen, é o AW com inverno seco e verão chuvoso. As amostras foram coletas no mês de abril de 2009, no horto medicinal. Os dados climatológicos no mês da realização do estudo foram fornecidos pela Estação Climatológica do ICA/UFMG. A temperatura manteve uma média de $23,9^{\circ} \mathrm{C}$ com a temperatura máxima de $27,8^{\circ} \mathrm{C}$ e mínima de $19,9^{\circ} \mathrm{C}$, precipitação de $71 \mathrm{~mm}$, umidade relativa de $86 \%$. O solo do horto medicinal foi classificado como argiloso vermelho-amarelo, originalmente sob vegetação de Cerrado, cuja análise apresentou em suas características químicas e físicas na camada de $0-20 \mathrm{~cm}$ de profundidade: $\mathrm{pH}$ em água $=4,8 ; \mathrm{K}=10 \mathrm{mmolc} \cdot \mathrm{dm}^{-3} ; \mathrm{Ca}=8 \mathrm{mmolc} \cdot \mathrm{dm}^{-3} ; \mathrm{Mg}=$ 3 mmolc. $\mathrm{dm}^{-3} ; \mathrm{Al}=20 \mathrm{mmolc} . \mathrm{dm}^{-3} ; \mathrm{SB}=21 \mathrm{mmolc}$. $\mathrm{dm}^{-3} ; \mathrm{T}=48 \mathrm{mmolc} \cdot \mathrm{dm}^{-3} ; \mathrm{V}=33 \% ; \mathrm{MOS}=18 \mathrm{~g} \cdot \mathrm{kg}^{-1}$; areia $=800 \mathrm{~g} \cdot \mathrm{kg}^{-1}$; silte $=120 \mathrm{~g} \cdot \mathrm{kg}^{-1}$; argila $=80 \mathrm{~g} \cdot \mathrm{kg}^{-1}$. Os tratos culturais utilizados na manutenção das plantas são: capina manual, irrigação por microaspersão, possuindo um espaçamento $5 \mathrm{~m}$, e associadas a outras plantas medicinais, como alfavaca-cravo (Ocimum gratissimum), erva-cidreira (Lippia alba), alecrimpimenta (Lippia sidoides).

Foram realizados dois experimentos no mês de abril de 2009, quando as plantas estavam em frase vegetativa, sendo coletadas amostras de $100 \mathrm{~g}$ da parte aérea para cada variável analisada, com cinco repetições em delineamento experimental blocos casualizados. Para o primeiro, verificou-se a influência do horário de coleta, os cinco tratamentos foram constituídos pelos seguintes horários de coleta: $6 \mathrm{~h}, 9 \mathrm{~h}, 12 \mathrm{~h}, 15 \mathrm{~h}, 18 \mathrm{~h}$. O segundo estudo, a orientação geográfica e dossel, onde foram coletadas amostras nas orientações, norte, sul, leste, oeste e nos dosséis apical, médio e basal, sendo doze tratamentos. As amostras de material vegetal fresco colhido foram congeladas, em seguidas submetidas à extração do óleo essencial no Laboratório de Plantas Medicinais e Aromáticas, pelo método de hidrodestilação, utilizando aparelho tipo Clevenger, por três horas. O teor de óleo essencial foi determinado com base na massa seca das amostras, que foram acondicionadas em estufa de circulação forçada a $60^{\circ} \mathrm{C}$, até peso constante. Os dados obtidos do horário de coleta foram submetidos à análise de variância, ajustados a regressões polinomiais, sendo os dados em função da orientação geográfica e dosséis submetidos à análise de variância, em esquema fatorial $4 \times 3$ (quatro orientações e três dosséis) e as médias comparadas pelo teste Scott-Knott à 5\% de probabilidade. O teor de óleo essencial foi transformado em arco-seno $\sqrt{X / 100}$. Para as análises utilizou-se o software SAEG (RIBEIRO JÚNIOR, 2001).

\section{Resultados e Discussão}

Foram observadas diferenças significativas na produção de óleo essencial de $C$. verbenacea em função do horário de coleta. O rendimento do óleo essencial com base na massa seca está apresentado na Figura 1. Os teores das amostras óleo essencial, foram de $0,65 \%$, $0,90 \%, 0,82 \%, 0,47 \%$ e $0,96 \%$, nos horários $6 \mathrm{~h}, 9 \mathrm{~h}, 12 \mathrm{~h}$, $15 \mathrm{~h}$ e $18 \mathrm{~h}$, respectivamente, sendo o horário de $18 \mathrm{~h}$ que forneceu o maior teor de óleo.

Resultados contrários encontrados para as espécies Andropogon sp. (NASCIMENTO et al., 2006) e Cymbopogon winterianus Jowitt que avaliaram também as estações do ano (BLANK et al., 2007), que recomendaram o período da manhã para a extração de óleo essencial. De acordo com Santos e Innecco (2003), no decorrer do dia podem ocorrer variações da intensidade luminosa e da temperatura atuando diretamente em processos primários, como fotossíntese e respiração, e podem influenciar indiretamente a produção de metabólitos secundários, entre eles os constituintes do óleo essencial, cuja síntese depende de produtos do metabolismo primário. A intensidade da luz pode, também, alterar a produção de óleo essencial através de ativação de enzimas fotossensíveis envolvidas na rota do ácido mevalônico, precursor dos terpenos que são constituintes químicos das essências. Constatou-se que o horário das $15 \mathrm{~h}$ não favoreceu o rendimento de óleo essencial. 


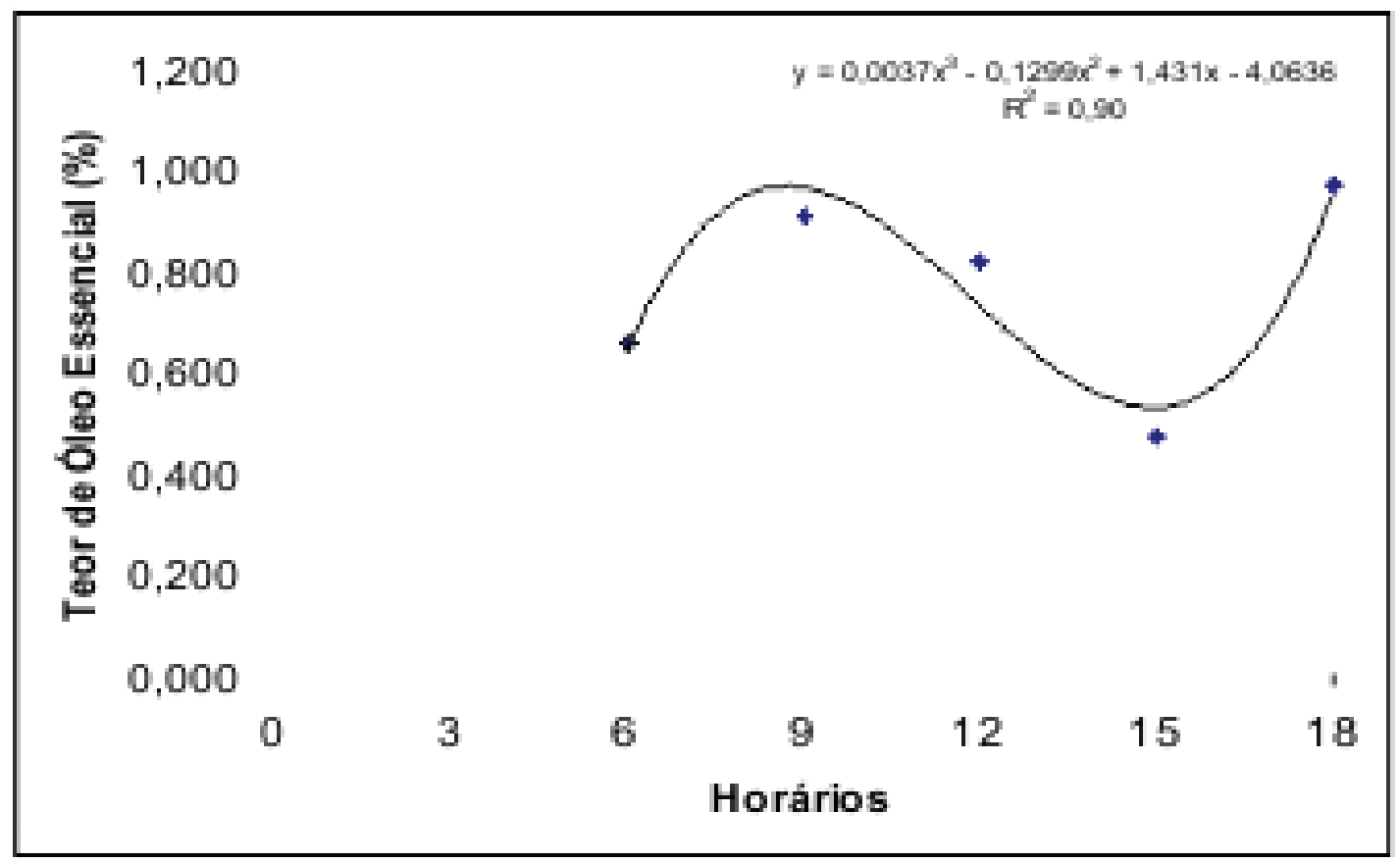

FIGURA 1: Teor (\%) de óleo essencial de Cordia verbenacea em diferentes horários de coleta, com base na massa seca.

Houve interação significativa dos fatores avaliados, e as amostras coletadas da orientação norte e sul basal forneceram maior teor de óleo essencial. Os teores nas orientações geográficas e dosséis da planta estão dispostos na Tabela 1.

TABELA 1: Teor (\%) do óleo essencial de C. verbenacea nas diferentes orientações geográficas e dosséis, com base na massa seca.

\begin{tabular}{ccccc}
\hline Dossel & \multicolumn{4}{c}{ Orientação } \\
\hline & Norte & Sul & Leste & Oeste \\
\hline Apical & $0,88 \mathrm{Ab}$ & $0,63 \mathrm{Bb}$ & $0,83 \mathrm{Ac}$ & $0,43 \mathrm{Bc}$ \\
Médio & $0,74 \mathrm{Ac}$ & $0,98 \mathrm{Ba}$ & $0,86 \mathrm{Bb}$ & $0,78 \mathrm{Ba}$ \\
Basal & $0,98 \mathrm{Aa}$ & $1,00 \mathrm{Aa}$ & $0,91 \mathrm{Ba}$ & $0,74 \mathrm{Cb}$ \\
\hline
\end{tabular}

* Mesmas letras maiúsculas nas linhas e minúsculas nas colunas não diferem estatisticamente pelo teste $\operatorname{Scott-Knott~}(p<0,05)$.

O crescimento vegetativo, idade foliar, temperatura, intensidade e duração da radiação solar podem alterar a produção de óleos essenciais (FAROOQI et al., 1999). Apesar de cada espécie ter se adaptado ao seu hábitat, as plantas frequentemente são capazes de existir em uma considerável faixa de temperatura. A faixa em que ocorrem as variações anuais, mensais e diárias na temperatura é um dos fatores que exerce maior influência em seu desenvolvimento, afetando, portanto, a produção de metabólitos secundários (EVANS, 1996). Fatores fisiológicos críticos, tais como fotossíntese, comportamento estomatal, mobilização de reservas, expansão foliar e crescimento, podem ser alterados por estresse hídrico e, consequentemente, levar a alterações no metabolismo secundário (BAZAAZ et al., 1987; SALISBURY; ROSS, 1991). Em várias espécies medicinais, a produção de óleo essencial tende a diminuir quando a radiação é menor ao passo que o estresse hídrico pode aumentar, diminuir ou não alterar a produção de metabólitos secundários (CARVALHO; CASALI, 1999). A radiação é um importante fator que pode interferir na produção e na qualidade dos óleos essenciais através da fotossíntese, da modulação do fotoperíodo e da qualidade da luz (SANGWAN et al., 2001). O nível de sombreamento das plantas também interfere no rendimento de óleos essenciais (MUNIRAN et al., 1999). A formação de óleos voláteis, em geral, parece aumentar em temperaturas mais elevadas, apesar de dias muito quentes levarem a uma perda excessiva destes metabólitos (EVANS, 1996). As concentrações de algumas substâncias componentes do óleo essencial de Santolina rosmarinifolia, entretanto, mostram uma correlação negativa com a temperatura 
(PALÁ-PAÚL et al., 2001). Portanto, observa-se neste trabalho que a colheita em diferentes horários ao longo do dia influenciaram na produção de óleo essencial de C. verbenaceae. Sendo o maior teor, o obtido no horário das $18 \mathrm{~h}$, com base na massa da matéria seca, e para a orientação geográfica e dossel, este foi obtido no norte e sul basal. Estes dados juntamente com resultados de estudos dos demais fatores que afetam o rendimento, poderão contribuir para definição de práticas de colheitas, gerando suporte para produzir óleo essencial que atenda aos padrões exigidos pelo mercado e formulações de medicamentos e fitoterápicos. Aconselha-se que novos trabalhos sejam desenvolvidos em diferentes épocas do ano, uma vez que este é um dos fatores de maior importância, visto que a quantidade e a natureza dos constituintes ativos não são constantes durante o ano. São relatadas, por exemplo, variações sazonais no conteúdo de praticamente todas as classes de metabólitos secundários, como óleos essenciais (ROBINSON, 1974; PITAREVIC et al., 1984), lactonas sesquiterpênicas (SCHMIDT et al., 1998; ZIDORN; STUPPNER, 2001), ácidos fenólicos (GRACE et al., 1998; ZIDORN e STUPPNER, 2001), flavonóides (JALAL et al., 1982; BROOKS; FEENY, 2004), saponinas (KIM et al., 1981; NDAMBA et al., 1994) e alcalóides (ROBINSON, 1974; ELGORASHI et al., 2002; ROCA-PÉREZ et al., 2004).

\section{Referências}

BASILE, A. C.; ERIÉ, J. A. A.; OSHIRO, T.; CALY, K. D. V.; PANIZZA, S. Topical anti-inflamatory activity and toxicity of Cordia verbenacea. Fitoterapia, Milan, v. 60, n. 3, p. 260-263, 1989.

BAZAAZ, F.; CHIARIELlO, N.; COLEY, P.; PITELKA, L. Allocating resources to reproduction and defense. BioScience, Uberlândia, v. 37, p. 58-67, 1987.

BLANK, A. F.; COSTA, A. G.; ARRIGONI-BLANK, M. F.; CAVALCANTI, S. C. H.; ALVES, P. B.; INNECCO, R.; EHLERT, P. A. D.; SOUSA, I. F. Influence of season, harvest time and drying on Java citronella (Cymbopogon winterianus Jowitt) volatile oil. Revista Brasileira de Farmacognosia, Curitiba, v. 17, p. 557564, 2007.

BROOKS, J. S.; FEENY, P. P. Seasonal variation in Daucus carota leaf-surface and leaf- tissue chemical profiles. Biochemical Systematics and Ecology, Maryland Heights, v. 32, p. 769-782, 2004.

CARVAlho, L. M.; CASALI, V. W. D. Plantas medicinais e aromáticas: relações com luz, estresse e insetos. Viçosa: UFV, 1999. $148 \mathrm{p}$.
CARVALHO JR., P. M.; RODRIGUES, R. F. O.; SAWAYA, A. C. H. F.; MARQUES, M. O. M.; SHIMIZU, M. T. Chemical composition and antimicrobial activity of the essential oil of Cordia verbenacea DC. Journal of Ethnopharmacology, Shannon, v. 95, p. 297-301, 2004.

FANTINI, A. C.; REIS, A.; REIS, M. S.; GUERRA, K. M. P. Sustained yield management in tropical forest: a proposal based on the authoecology of the species. Selowia, Itajaí, v. 42, n. 44, p. $25-$ 33, 1992.

FAROOQI, A. H. A.; SANGWAN, N. S.; SANGWAN, R. S. Effect of different photoperiodic regimes on growth, flowering and essential oil in Mentha species. Plant Growth Regulation, Kent, v. 29, p. 181-187, 1999.

ELGORASHI, E. E.; DREWES, S. E.; STADEN, J. V. Organ-toorgan and seasonal variation in alkaloids from Crinum macowanii. Fitoterapia, Milan, v. 73, p. 490-495, 2002.

EVANS, W. C. Trease and Evans' Pharmacognosy. 14 ed. London: WB Saunders Company, 1996. 612 p.

FAIRBAIRN, J. W.; SUWAL, P. N. The alkaloids of hemlock (Conium maculatum L.). II. Evidence for a rapid turnover of the major alkaloids. Phytochemistry, Leiden, v. 1, p. 38-46, 1961.

GOBBO-NETO, L.; LOPES, N. P. Plantas medicinais: fatores de influência no conteúdo de metabólitos secundários. Química Nova, São Paulo, v. 30, p. 374-381, 2007.

GRACE, S. C.; LOGAN, B. A.; ADAMS III, W. W. Seasonal differences in foliar content of chlorogenic acid, a phenylpropanoid antioxidant, in Mahonia repens. Plant, Cell and Environment, v. 21, p. 513-521, 1998.

HARTMANN, T. Diversity and variability of plant secondary metabolism: a mechanistic view. Entomologia Experimentalis et Applicata, v. 80, p. 177-188, 1996.

JALAL, M. A. F.; READ, D. J.; HASLAM, E. Phenolic composition and its seasonal variation in Calluna vulgaris. Phytochemistry, Leiden, v. 21, p. 1397-1401, 1982.

KIM, S. K.; SAKAMOTO, I.; MORIMOTO, K.; SAKATA, M.; YAMASAKI, K.; TANAKA, O. Seasonal variation of saponins, sucrose and monosaccharides in cultivated ginseng roots. Planta Medica, Stuttgart, v. 42, p. 181-186, 1981.

KUTCHAN, T. M. Ecological arsenal and developmental dispatcher. The paradigm of secondary metabolism. Plant Physiology, Maryland, v. 125, p. 58-60, 2001.

LINDROTH, R. L.; HSIA, M. T. S.; SCRIBER, J. M. Seasonal patterns in the phytochemistry of three Populus species. Biochemical Systematics and Ecology, Maryland Heights, v. 15, p. 681-686, 1987.

LINS, A. P.; ALVARENGA, M. A.; GOTTLIEB, O. R.; OLIVEIRA, F. Two flavonoids from Cordia verbenacea. Revista LatinoAmericana de Química, v. 21, n. 2, p. 82, 1990.

LORENZI, H.; MATOS, F. J. A. Plantas medicinais do Brasil: nativas e exóticas. 3 ed. Nova Odessa: Instituto Plantarum, 2002. $512 \mathrm{p}$.

LOURENZANI, A. E. B. S.; LOURENZANI, W. L.; BATALHA, M. O. Barreiras e oportunidades na comercialização de plantas medicinais provenientes da agricultura familiar. Informações Econômicas, São Paulo, v. 34, p. 15-25, 2004. 
MING, L. C. Estudo e pesquisa de plantas medicinais na agronomia. Horticultura Brasileira, Campinas, v. 1, n. 12, p. 2-9, 1994.

MUNI-RAN, D. R.; SANTOSH, S.; NAQVI, A. A., SUSHIL, K. Studies on intercropping of patchouli (Pogostemon patchouli) with papaya (Carica papaya). Journal of Medicinal and Aromatic Plant Science, v. 21, n. 2, p. 358-360, 1999.

NASCIMENTO, I. B.; INNECO, R.; MATOS, S. H.; BORGES, N. S. S.; MARCO, C. A. Influência do horário de coleta na produção de óleo essencial de capim santo (Andropogum sp.). Revista Caatinga, Mossoró, v. 19, p. 123-127, 2006.

NDAMBA, J.; LEMMICH, E.; MØLGAARD, P. Investigation of the diurnal, ontogenetic and seasonal variation in the molluscicidal saponin content of Phytolacca dodecandra aqueous berry extracts. Phytochemistry, Leiden, v. 35, p. 95-99. 1994.

NOGUEIRA, J. C. M.; WOLFF, C. K. Na luta pela produção socialmente saudável - que remédio? Acúmulos, riscos e potenciais na inter-relação entre plantas medicinais e agricultura familiar - IFAS. 2001. Disponível em <http://ifas.org.br/html/ mais/t artigo/dados/producao socialmente sust art revist $2 . \mathrm{htm}>$. Acesso em: 22 agosto 2009.

PASSOS, G. F.; FERNANDES, E. S.; DA CUNHA, F. M. F.; FERREIRA, J.; PIANOWSKI, L. F.; CAMPOSAS, M. M.; CALIXTO, C. J. B. Anti-inflamatory and anti- allergic properties of the essential oil and active compounds from Cordia verbenacea. Journal of Ethnopharmacology, Shannon, v. 110, p. 323-333, 2007.

PALÁ-PAÚl， J.; PÉREZ-ALONSO, M. J.; VELASCONEGUERUELA, A.; PALÁ-PAÚL, R.; SANZ, J.; CONEJERO, F. Seasonal variation in chemical constituents of Santolina rosmarinifolia L. ssp. rosmarinifolia. Biochemical Systematics and Ecology, Maryland Heights, v. 29, p. 663-672, 2001.

PITAREVIC., I.; KUFTINEC, J.; BLAŽEVIC. , N.; KUŠTRAK, D. Seasonal variation of essential oil yield and composition of Dalmatian sage, Salvia officinalis. Journal of Natural Products, Columbus, v. 47, p. 409-412, 1984.

RIBEIRO JÚNIOR, J. I. Análises estatísticas no SAEG. Viçosa: UFV, 2001. $301 \mathrm{p}$

ROBINSON, T. Metabolism and function of alkaloids in plants. Science, New York, v. 184, p. 430-435, 1974
ROCA-PÉREZ L.; BOLUDA R.; GAVIDIA I; PÉREZBERMÚDEZ P. Seasonal cardenolide production and Dop $5 \beta \mathrm{r}$ gene expression in natural populations of Digitalis obscura. Phytochemistry, Leiden, v. 65, p. 1869-1878, 2004.

SALISBURY, F. B.; ROSS, C. W. Plant Physiology. 4 ed. Belmont: Wadsworth Publishing Co., 1991. 682 p.

SANGWAN, N. S.; FAROOQI, A. H. A.; SFIABIH, F.; SANGWAN, R. S. Regulation of essential oil production in plants. Plant Growth Regulation, Kent, v. 34, p. 3-21, 2001.

SANTOS, M. R. A.; INNECO, R. Influência de períodos de secagem de folhas de óleo essencial de erva-cidreira (quimiotipo limoneno-carvona). Revista Ciência Agronômica, Fortaleza, v. 34 , p. 5-11, 2003.

SCHMIDT, T. J., BOMME, U., ALFERMANN, A.W.. Sesquiterpene lactone content in leaves in vitro and field-cultivated of Arnica montana. Planta Medica, Stuttgart, v. 64, p. 268-270, 1998

SERTIÉ, J. A. A.; WOISKY, R. G.; WIEZEL, G.; RODRIGUES, M. Pharmacological assay of Cordia verbenacea $\mathrm{V}$ : oral and topical anti-inflammatory activity, analgesic effect and fetus toxicity of a crude leaf extract. Phytomedicine, v.12, p. 338-344, 2005.

SOUZA, G. C.; HAAS, A. P. S.; VON POSER, G. L.; SCHAPOVAL, E. E. S.; LISABETSKY, E. Ethnopharmacological studies of antimicrobial remedies in the south of Brazil. Journal of Ethnopharmacology, Shannon, v. 94, p. 135-143, 2004.

TAIZ, L.; ZEIGER, E. Fisiologia Vegetal. 3 ed. Porto Alegre: Artmed, 2004. $719 \mathrm{p}$

TESKE, M.; TRENTINI, A. M. M. Herbarium compêndio de fitoterapia. 3 ed. Curitiba: Herbarium Laboratório Botânico, 1997. $317 \mathrm{p}$.

ZARONI, M.; PONTAROLO, R.; ABRAHÃO, W. S. M.; FAVERO, M. L. D.; CORREIA JÚNIOR, C.; STREMEL, D. P. Qualidade microbiológica das plantas medicinais produzidas no Estado do Paraná. Revista Brasileira de Farmacognosia, Curitiba, v. 14, n. 1, p. 29-39, 2004

ZIDORN, C., STUPPNER, H. Evaluation of chemosystematic characters in the genus Lentodon (Asteraceae). Taxon, v. 50, p. 115-133, 2001. 